\title{
Echinocystic Acid Inhibits Inflammation and Exerts Neuroprotective Effects in MPTP-Induced Parkinson's Disease Model Mice
}

\author{
Dewei $\mathrm{He}^{1 \dagger}$, Guiqiu $\mathrm{Hu}^{2+}$, Ang Zhou ${ }^{2 \dagger}$, Yanting $\mathrm{Liu}^{3+}$, Bingxu Huang ${ }^{2}$, Yingchun $\mathrm{Su}^{2}$, \\ Hefei Wang ${ }^{2}$, Bojian $\mathrm{Ye}^{2}$, Yuan $\mathrm{He}^{2}$, Xiyu Gao ${ }^{1}$, Shoupeng $\mathrm{Fu}^{2}$ and Dianfeng Liu ${ }^{1 *}$ \\ ${ }^{1}$ College of Animal Science, Jilin University, Changchun, China, ${ }^{2}$ College of Veterinary Medicine, Jilin University, Changchun, \\ China, ${ }^{3}$ Department of Neurosurgery, Seoul St. Mary's Hospital, College of Medicine, The Catholic University of Korea, Seoul, \\ South Korea
}

Parkinson's disease (PD), the second primary neurodegenerative disease affecting human health, is mainly characterized by dopaminergic neuron damage in the midbrain and the clinical manifestation of movement disorders. Studies have shown that neuroinflammation plays an important role in the progression of PD. Excessively activated microglia produce several pro-inflammatory mediators, leading to damage to the surrounding neurons and finally inducing neurodegeneration. Echinocystic acid (EA) exhibits an anti-inflammatory effect in peripheral tissues. However, whether it inhibited neuroinflammation remains unclear. Therefore, the current study investigates the effect of EA on neuroinflammation and whether it can improve PD symptoms through inhibiting neuroinflammation. In our experiments, we discovered that EA inhibited the production of pro-inflammatory mediators in LPS-exposed BV2 cells. Further mechanism-related studies revealed that EA inhibited inflammation by activating PI3K/Akt and inhibiting NF- $\kappa B$ and MAPK signal pathways in LPS-induced BV2 cells. Research revealed that EA eases microglia-mediated neuron death in SN4741 and SHSY5Y cells. In in vivo studies, the results demonstrated that EA improves weight loss and behavioral impairment in MPTPinduced mice. Further studies have revealed that EA inhibited dopaminergic neuron damage and inflammation in the mice midbrain. In conclusion, our study demonstrated that EA inhibits neuroinflammation and exerts neuroprotective effects by activating PI3K/ Akt and inhibiting NF-kB and MAPK signal pathways in vivo and in vitro.

Keywords: Parkinson's disease, neuroinflammation, echinostic acid, microglia, NF-kB/MAPK

\section{INTRODUCTION}

Parkinson's disease (PD) is the second most prevalent neurodegenerative disorder, and its clinical manifestations are mainly motor symptoms such as resting tremor and muscle rigidity. Studies have shown that the combined effects of aging, genetics, and environmental factors lead to the onset of PD (Pollak, 2004; Nakano-Kobayashi et al., 2020; Ramli et al., 2020). However, the specific etiology of PD is not fully understood. At present, the commonly used clinical treatment methods mainly focus on 
rehabilitation training to assist drug therapy, but the rehabilitation training has little effect on severely ill patients. The commonly used clinical drugs have limited effects, and their long-term use has strong side effects (Bomalaski et al., 2017; Houman, 2018; Elkouzi et al., 2019). Therefore, exploring the pathogenesis of $\mathrm{PD}$ and discovering effective and alleviating drugs for PD treatment are required.

The main pathological features of PD are the formation of Lewy bodies and loss of dopaminergic neurons in the midbrain. An increasing number of evidence showed that the course of PD is accompanied by neuroinflammation, and excessive inflammation will in turn exacerbate PD. During the neuroinflammation process, immune cells are activated to release inflammatory mediators, damaging peripheral neurons. Long-term continuous damage leads to degeneration and loss of several dopaminergic neurons, exhibiting PD symptoms (Lee et al., 2009; Bartels and Leenders, 2010; Chung et al., 2010; Pereira et al., 2018). Microglia, the resident immune cells of the brain, are the main participants of neuroinflammation. The autopsy report also showed that several microglial cells were activated in the midbrain of patients with PD (Alstadhaug et al., 2017; Hopperton et al., 2017). Excessively activated microglia produce several pro-inflammatory mediators, leading to damage to surrounding neurons and finally inducing neurodegeneration. Therefore, inhibiting the excessive activation of microglia and the neuroinflammatory response involved might have a certain effect on alleviating PD.

Lipopolysaccharide (LPS) is a component of the cell wall of Gram-negative bacteria. Studies have shown that LPS stimulation can activate the inflammatory response in immune cells through Toll-like receptor 4 (TLR4) (Huang et al., 1995; Lu et al., 2008). In this experiment, we treated BV2 cells with LPS to induce an in vitro microglia inflammation model. 1-Methyl-4-phenyl-1, 2, 3, 6-tetrahydropyridine hydrochloride (MPTP) is a lipophilic toxin that can penetrate the blood-brain barrier. After entering the brain, MPTP is converted to 1-methyl-4phenylpyridine $\left(\mathrm{MPP}^{+}\right)$by monoamine oxidase $\mathrm{B}$ and damages neurons (Kan et al., 1984; Przedborski et al., 1996). In the experiment, we injected MPTP into the abdominal cavity to construct a PD mouse model.

Echinocystic acid (EA), derived from Albizzia julibrissin Durazz (Fabaceae) inflorescence (Shao et al., 1996; Dhaneshwar et al., 2010; Liu et al., 2017), exhibits a spectrum of pharmacological effects, such as liver and blood nourishment, blood coagulation, and immune regulation activity. As a natural compound, EA has the advantages of small side effects and easy availability. Therefore, EA effects are widely studied in various diseases. Recently, many studies have shown that EA exhibits excellent anti-inflammatory, antioxidant, and antitumor effects (Jæger et al., 2017; Fu et al., 2018). Studies found that EA inhibits macrophage inflammation and improves LPS-induced acute lung injury in mice via the NF- $\kappa$ B and MAPK pathways (Joh et al., 2012; Deretic, 2021). Studies have also revealed that EA alleviates cerebral ischemia/reperfusion injury by inhibiting the JNK signaling pathway (Yu et al., 2019). In addition, EA can inhibit cerebral ischemia via the PI3K/Akt pathway in intracerebral hemorrhage mice (Chen et al., 2020). We assume that EA might inhibit neuroinflammation and exert a neuroprotective effect in $\mathrm{PD}$ based on the aforementioned findings.

\section{METHODS AND MATERIALS}

\subsection{Reagents}

Echinocystic acid (EA, $>98.0 \%$ purity; Shanghai Yuan-ye, St. Louis, Shanghai, China), lipopolysaccharide (LPS, Sigma, St. Louis, MO, United States), dimethyl sulfoxide (DMSO), LY294002 (a PI3K inhibitor), and MK2206 (an Akt inhibitor) were obtained from Sigma Aldrich (St Louis, MO, United States). Dulbecco's modified Eagle's medium (DMEM) and fetal bovine serum (FBS) were obtained from Gibco (Grand Island, NY, United States). Penicillin-streptomycin (PS) solutions were obtained from Invitrogen (Carlsbad, CA, United States). Trypsin was obtained from Beyotime Institute (Biotech, Beijing, China).

\subsection{Cell Culture and Treatment}

BV2 (murine microglia cell line), SN4741 (murine dopaminergic neuron cell line), and SHSY5Y (human neuroblastoma cell line) were obtained from Shanghai Binsui Biological Technology (Shanghai, China). The cultured conditions of cells were as follows: $89 \%$ DMEM $+10 \% \quad \mathrm{FBS}+1 \%$ penicillin-streptomycin (PS) solutions, $95 \%$ air, 5\% carbon dioxide (CO2), and a temperature of $37^{\circ} \mathrm{C}$. The cells were digested with 0.25 and $0.05 \%$ trypsin, and passaged every 2 days. The cells were seeded into a $6-\mathrm{cm}$ diameter cell culture dish during the research period. When the density was $70-80 \%$, the medium was replaced with serum-free DMEM, and then EA was added to the petri dish and incubated for $1 \mathrm{~h}$. Later, the cells were exposed to LPS $(100 \mathrm{ng} / \mathrm{ml})$ for 1,12 , and $24 \mathrm{~h}$. During the experiment, SN4741and SHSY5Y cells were cultured in a conditioned medium.

\subsection{CCK-8 Assay}

Cells were seeded into 96-well plates at a density of $1-2 \times 10^{4}$ cells per well and cultured overnight in a cell incubator. When the density was moderate, different concentrations of EA and solvent DMSO were added to the culture wells and then cultured. After $24 \mathrm{~h}$, the culture medium was replaced with CCK8 dilution (Beyotime Inst Biotech, Beijing, China) and incubated for $2 \mathrm{~h}$. After that, cell viability was measured with a microplate reader at $450 \mathrm{~nm}$.

\subsection{LDH Assay}

Cells were seeded into 96-well plates at a density of $1-2 \times 10^{4}$ cells per well and cultured overnight in a cell incubator. Different concentrations of EA and solvent DMSO were added to the culture wells, and then the cells were cultured. After $24 \mathrm{~h}$, the release of $\mathrm{LDH}$ in the medium was determined using an $\mathrm{LDH}$ assay kit (Beyotime Inst Biotech, Beijing, China) according to the manufacturer's instructions. 
TABLE 1 | Primer sequences for quantitative PCR.

\begin{tabular}{ll}
\hline Gene & \multicolumn{1}{c}{ Sequences } \\
\hline IL-6 & (F) 5'-CCAGAACCGCTATGAAGTTCC-3' \\
& (R) 5'-GTTGGGAGTGGTATCCTCTGTGA-3' \\
(F): 5'-ACGGCATGGATCTCAAAGAC-3' & (R): 5'-GTGGGTGAGGAGCACGTAGT-3' \\
iNOS & (F) 5'-GAACTGTAGCACAGCACAGGAAAT-3' \\
& (R) 5'-CGTACCGGATGAGCTGTGAAT-3' \\
COX-2 & (F) 5'-CAGTTATGTTGTCTGTCCAGAGTTC-3' \\
& (R) 5'-CCAGCACTTCACCCATCAGTT-3' \\
& (F): 5-GTCAGGTCATCACTATCGGCAAT-3 \\
& (R): 5-AGAGGTCTTTACGGATGTCAACGT-3
\end{tabular}

\subsection{Quantitative PCR}

According to the manufacturer's protocols, cells and tissue RNAs were extracted using the Trizol reagent (Invitrogen, Carlsbad, CA, United States). After determining the concentration, $2 \mu \mathrm{g}$ RNA was reverse-transcribed into cDNA using a reverse transcription kit (Sigma-Aldrich, St. Louis, MO,
United States). Then quantitative PCR (qPCR) was performed using the SYBR Green QuantiTect RT-PCR Kit (Invitrogen, Carlsbad, CA, United States), according to the manufacturer's protocols. The mRNA levels of inflammatory mediators were evaluated relative to $\beta$-actin according to the $2^{-\Delta \Delta C T}$ method. The primers involved in the experiment are presented in Table $\mathbf{1}$.

\subsection{ELISA}

When the cells seeded into a 24 -well plate were $70-80 \%$ in density, the medium was changed to serum-free DMEM. Then the cells were incubated with EA $(1 \mathrm{~h}, 16 \mu \mathrm{M})$ and stimulated with LPS $(100 \mathrm{ng} / \mathrm{ml}, 24 \mathrm{~h})$. After that, the expression of IL-6 and TNF- $\alpha$ in the supernatant was measured using the ELISA kits, according to the manufacturer's protocols (BioLegend, San Diego, CA, United States).

\subsection{Western Blot}

Total protein of BV2 cells and mice midbrain tissue was extracted using P0013 Lysis Solution (Beyotime Ist. Beijing, China). Protein concentration was measured using a BCA reagent (Beibo Biological

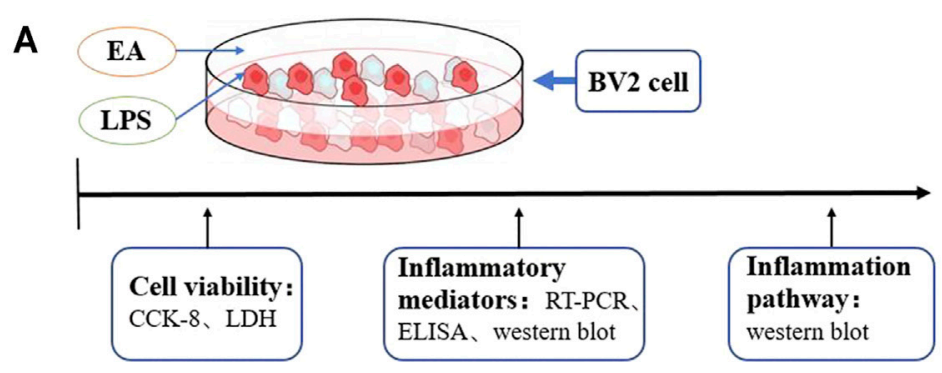

B<smiles>CC1(C)CCC2(C(=O)O)C(O)C[C@]3(C)C(=CCC4C5(C)CC[C@H](O)C(C)(C)C5CCC43C)C2C1</smiles>

Echinocystic acid

Chemical formula: $\mathrm{C}_{30} \mathrm{H}_{48} \mathrm{O}_{4}$

Molecular weight: 472.71
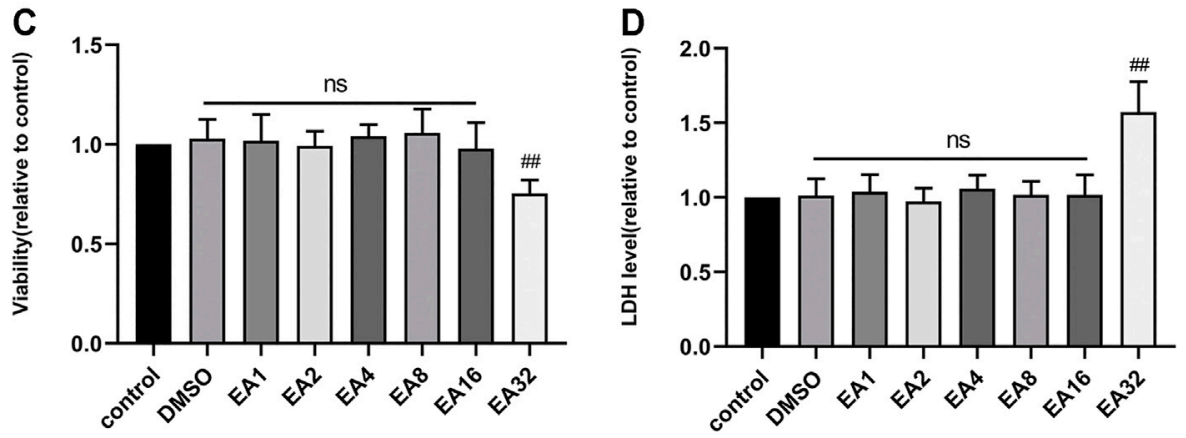

FIGURE 1 | Effect of EA on the viability of BV2 cells. (A) Processing of BV2 cells. (B) The structure of EA. (C) The survival rate of BV2 cells treated with different concentrations of EA $(1,2,4,8,16$, and $32 \mu \mathrm{M})$ for $24 \mathrm{~h}$ via CCK-8 experiment. (D) Effects of EA on LDH release in BV2 cells. Results are represented as means \pm SD $(n=4) .{ }^{\# \#} p<0.01$ vs. control group. 

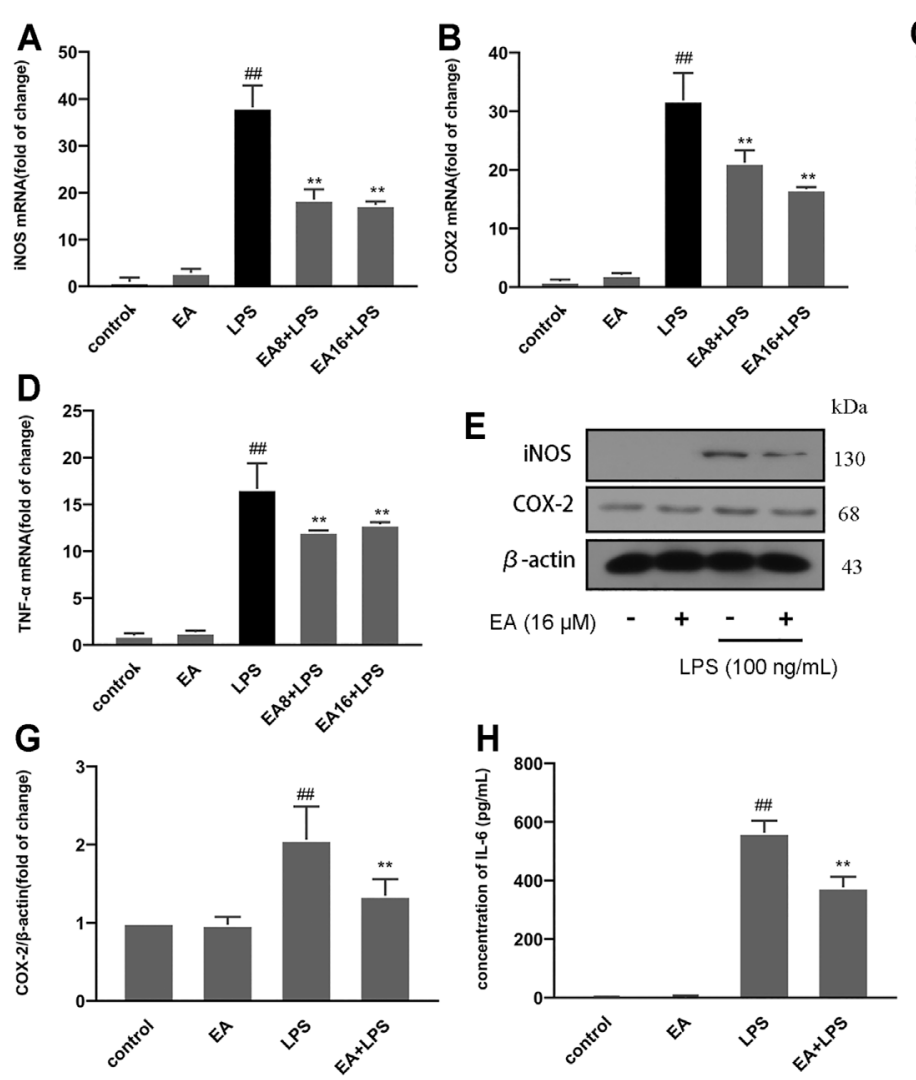
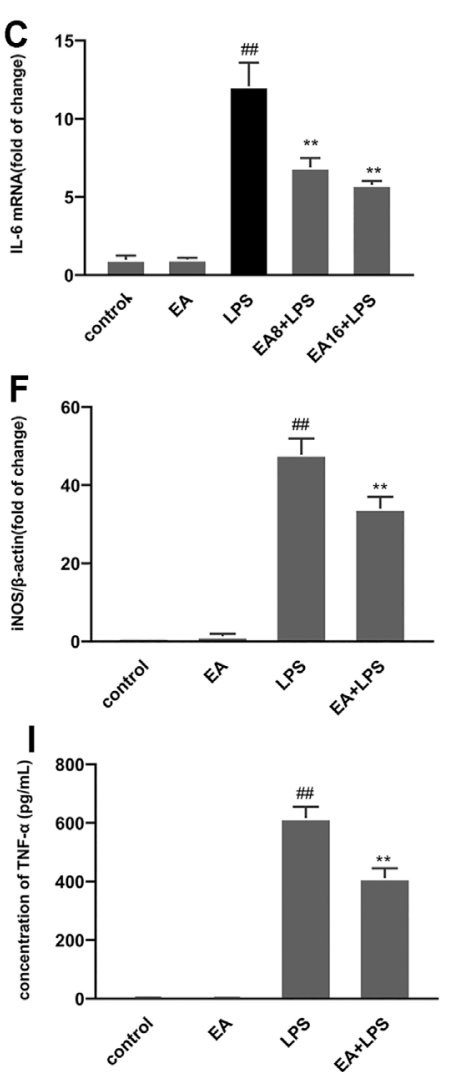

FIGURE 2 | EA inhibits the production of inflammatory mediators. We treated BV2 cells for $1 \mathrm{~h}$ with EA (8 and $16 \mu \mathrm{M})$ and stimulated for $12 \mathrm{~h}$ with LPS (100 ng/ml). Then we examined the effect of EA on mRNA expression of inflammatory mediators [iNOS (A), COX-2 (B), IL-6 (C), and TNF- $\alpha$ (D)] via quantitative PCR experiment. We treated BV2 cells for $1 \mathrm{~h}$ with EA $(16 \mu \mathrm{M})$ and stimulated for $24 \mathrm{~h}$ with LPS (100 $\mathrm{ng} / \mathrm{ml})$. Then we examined the effect of EA on protein expression of inflammatory mediators [iNOS (E,F), COX-2 (E,G), IL-6 (H), and TNF- $\alpha \mathbf{( I )}$ ] via Western blot and ELISA experiment. Results are represented as means \pm SD $(n=4)$. ${ }^{\# \# ~} p<0.01$ vs. control group. ${ }^{* *} p<0.01$ vs. LPS-exposed group.

Technology, Shanghai, China). The $30 \mu \mathrm{g}$ protein was loaded and separated by $13 \%$ SDS-PAGE, and then transferred to polyvinylidene difluoride (PVDF) membranes (Biyuntian Biological Reagent, Beijing, China). After blocking with $5 \%$ skim milk for $2 \mathrm{~h}$ at room temperature, the PVDF membranes were incubated with primary antibodies [COX-2 (1:5,000), iNOS (1:5,000), p-Akt (1: 5,000) (Abcam, Cambridge, United Kingdom), p-JNK1/2 (1: 5,000), p-ERK1/2 (1:5,000) (Cell Signal Technology, MA, United States), p-p38 (1:5,000), p-NF-кB p65 (1:5,000), JNK1/2 (1: 5,000), ERK1/2 (1:5,000), p38 (1:5,000), Akt (1:5,000), NF-кB p65 (1: $5,000)$, and $\beta$-actin $(1: 5,000)$ (Santa, CA, United States)] for $12 \mathrm{~h}$ at $4^{\circ} \mathrm{C}$ and then washed three times (20 min per time) with TBST solution. Thereafter, the membranes were incubated with the following secondary antibodies: goat anti-rabbit $(1: 5,000)$ and goat anti-mouse $(1: 5,000)$ (Santa, CA, United States) for $2 \mathrm{~h}$, and then washed three times ( $20 \mathrm{~min}$ per time) with TBST solution. All the primary antibodies and secondary antibodies were dissolved in a 5\% BSA solution. Next, the membranes were incubated with ECL Luminous Liquid (Amersham Pharmacia Biotech, Philadelphia, United States), and the target proteins were presented with the ScanLater Western Blot Detection System (Meigu Molecular Instruments, Shanghai, China).

\subsection{Animals and Treatment}

Forty male C57BL6 mice (25-30 g) were purchased from the Experimental Animals Center of Norman Bethune Medical College of Jilin University (Changchun, PR China). Animals were kept at $22-24^{\circ} \mathrm{C}$ in an artificial $12 / 12 \mathrm{~h}$ day/night cycle condition. All the animals were provided with adequate food and drink. Animal models were induced with 1-methyl-4-phenyl-1, 2, 3, 6tetrahydropyridine hydrochloride (MPTP, Sigma-Aldrich, MO, United States). The mice were randomly divided into three groups during the experiment: saline, MPTP, and MPTP + EA. MPTP (30 mg/kg, dissolved in saline) was injected intraperitoneally for $7 \mathrm{~d}$. EA (dissolved in saline) was administered intragastrically once a day for 17 days. After administration, the mice were tested through behavioral tests. After that, the mice were euthanized.

\subsection{Behavioral Tests 2.9.1 Open Field Test}

The mobility of mice was tested through the open field test. In the test, mice were placed into the box $(50 \times 50 \times 30 \mathrm{~cm}$, Any-maze, Stoelting Co.) for $5 \mathrm{~min}$. During this time, the total distance mice traveled and the time mice spent in the inner zones of the box were recorded with an overhead camera and analyzed using Top 

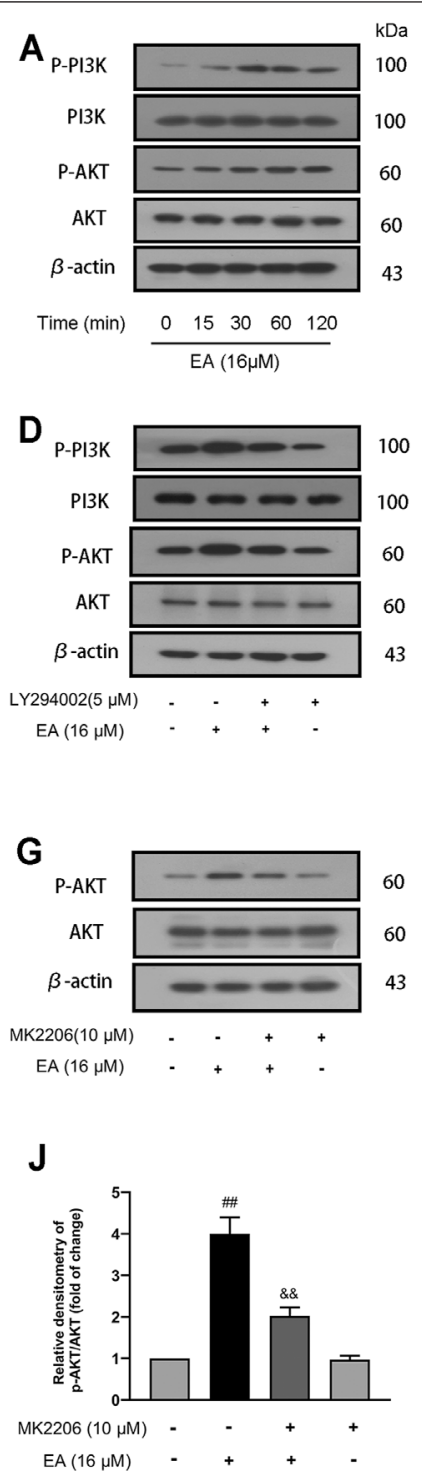
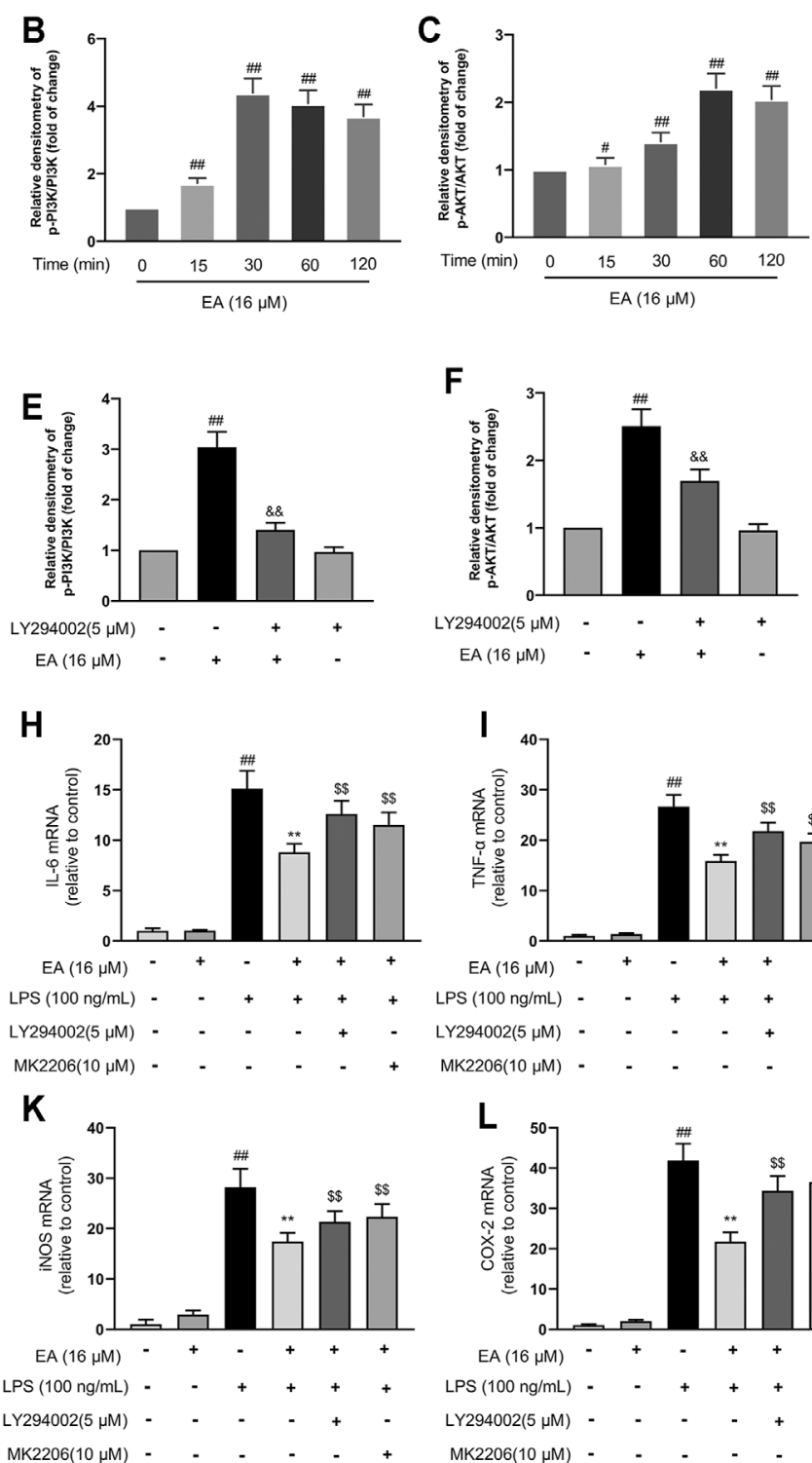

FIGURE 3 | EA inhibits inflammation through the PI3K/Akt signal pathway. We treated BV2 cells for $1 \mathrm{~h}$ with EA (16 $\mu \mathrm{M})$ and stimulated for $12 \mathrm{~h}$ with LPS (100 ng/ $\mathrm{ml})$. BV2 cells were treated for different times $(0,15,30$, and $60 \mathrm{~min})$ with $\mathrm{EA}(16 \mu \mathrm{M})$, and then the protein expression of $\mathrm{p}$-PI3K, PI3K, $\mathrm{p}$-AKt, Akt, and $\beta$-actin was examined via Western blot experiment (A-C). BV2 cells were treated for $6 \mathrm{~h}$ with LY294002 (a PI3K pathway inhibitor, $5 \mu$ M) or MK2206 (an Akt pathway inhibitor $10 \mu \mathrm{M})$, and then the protein expression of $\mathrm{p}-\mathrm{PI} 3 \mathrm{~K}, \mathrm{PI} 3 \mathrm{~K}, \mathrm{p}$-Akt, Akt, and $\beta$-actin was examined via Western blot experiment (D-H). Thereafter, we treated BV2 cells for $1 \mathrm{~h}$ with EA $(16 \mu \mathrm{M})$ and stimulated for $12 \mathrm{~h}$ with LPS (100 ng/ml), and then surveyed the effect of EA on the mRNA levels of inflammatory mediators [iNOS (K), COX-2 (L), IL-6 (I), and TNF- $\alpha$ (J)] via quantitative PCR experiment. Results are represented as means \pm SD $(n=4)$. ${ }^{\# \#} p<0.01$ vs. control group. ${ }^{* *} p<0.01$ vs. LPS-exposed group. ${ }^{\$ \$} p<0.01$ vs. LPS + EA group.

Scan software (Any-maze, Stoelting Co.), according to the manufacturer's instructions. We maintained a quiet environment during the experiment.

\subsubsection{Climbing Pole Experiment}

The mice were placed on the top of a wooden pole with a height of $60 \mathrm{~cm}$ and a diameter of $1 \mathrm{~cm}$ for the experiment of climbing the pole. The timing began when the hind legs of the mice left the top of the pole, and the timing stopped when the mice landed on the ground. The experiment was repeated three times for each mouse and the average value was recorded. The mice were trained to climb the pole every day for 1 week before the experiment.

\subsubsection{Turn bar Experiment}

The mice were put on the rotor-rod fatigue instrument, the rotorrod speed was adjusted so that the normal mice stayed on the rotor-rod for 60-90 s, and the rotor-rod speed was recorded as the setting value during the experiment. During the experiment, mice were placed on the rotary-rod fatigue instrument, the instrument was started, and the residence time of mice on the 

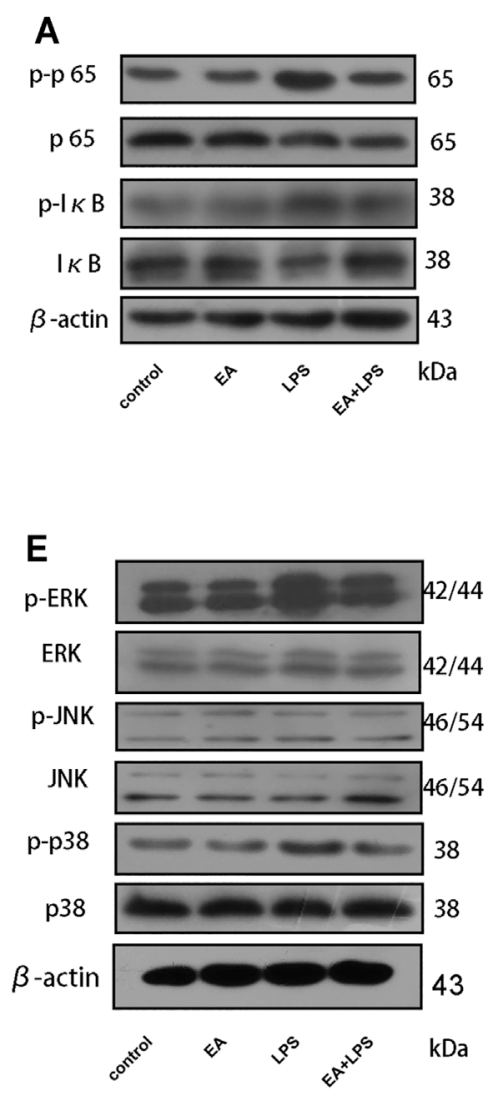
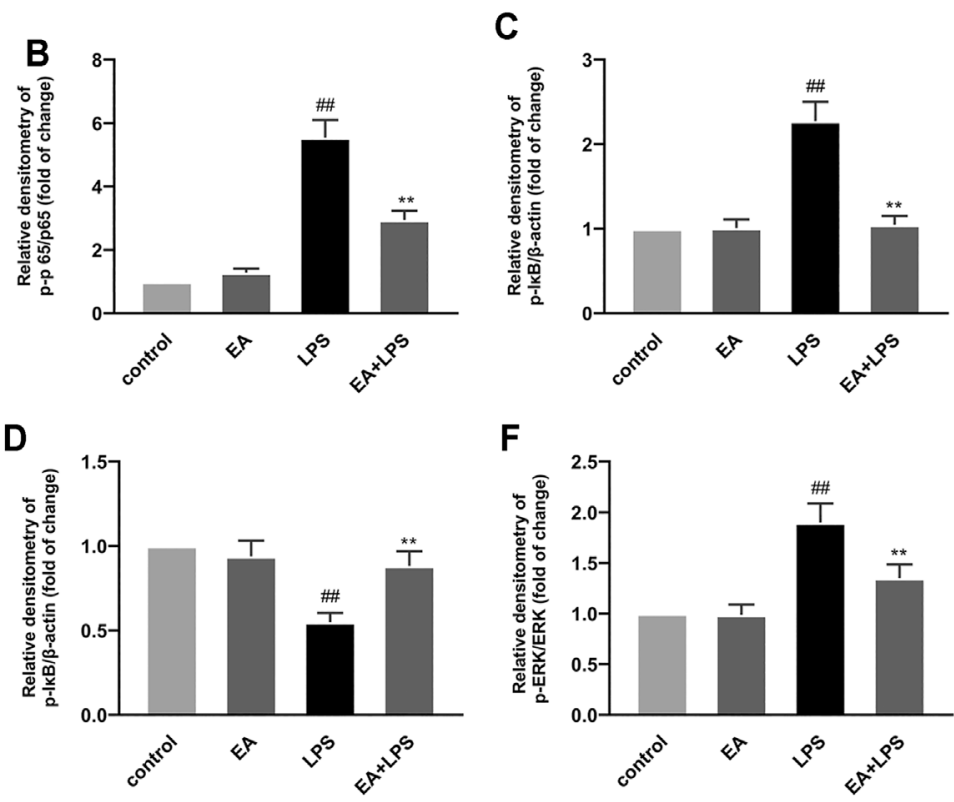

$\mathbf{F}$

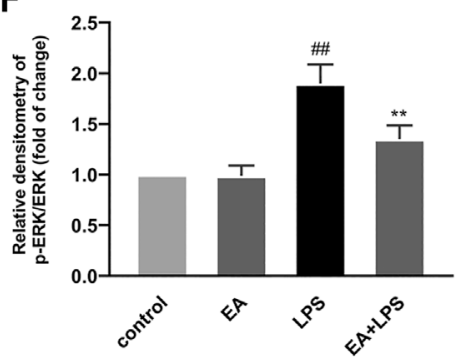

G

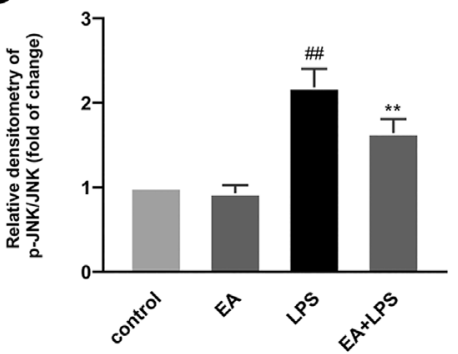

H

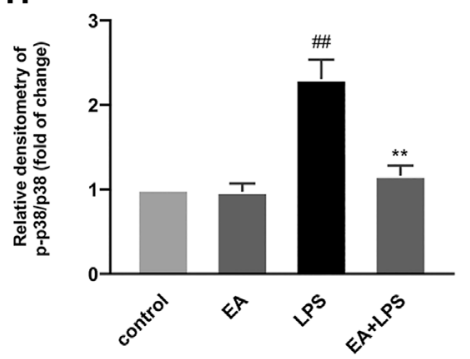

FIGURE 4 | EA inhibits NF-кB and MAPK signal pathway. We treated BV2 cells for $1 \mathrm{~h}$ with EA (16 $\mu \mathrm{M})$ and stimulated for $2 \mathrm{~h}$ with LPS (100 ng/ml). Then we

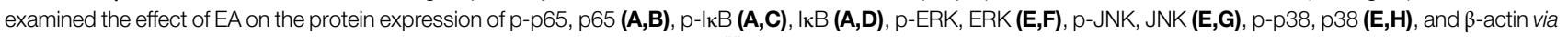
Western blot experiment. Results are represented as means $\pm \mathrm{SD}(n=4) .{ }^{\# \#} p<0.01$ vs. control group. ${ }^{\star *} p<0.01$ vs. LPS-exposed group.

rotary-rod was recorded by timing. Each mouse was put on the instrument three times, and the average value (residence time) was recorded. The mice were trained daily for 1 week before the experiment.

\subsection{Immunohistochemical Staining}

The number of dopaminergic neurons and microglia activation in the substantia nigra of the mouse midbrain were detected through immunohistochemical staining. In brief, after being euthanized, the midbrains of mice were soaked in a $4 \%$ paraformaldehyde solution for $24 \mathrm{~h}$, and then processed using the following procedure: alcohol $(70,80,90 \%$ each for $1 \mathrm{~h}, 100 \%$ for $2 \mathrm{~h})$, xylene (20 $\mathrm{min})$, and then dipping wax (40 $\mathrm{min})$. Then the tissues were sectioned at $5 \mu \mathrm{m}$ per slice. Thereafter, the immunohistochemistry staining was performed with an UltrasensitiveTM S-P kit (MBX Biotechnologies, Fuzhou, China), according to the manufacturer's protocols. The dopaminergic neurons were marked with the anti-TH and anti-IBA-1 antibodies (1:200, Abcam, Cambridge, United Kingdom). IHC images were taken under an optical microscope. Total TH-positive cells and IBA-1-positive cells were counted by five researchers blind to the experimental design, and the average of these scores was reported.

\subsection{Statistical Analysis}

Differences in data were analyzed using SPSS 19.0 software (IBM). All data were represented as means \pm SD. Differences of groups were calculated adopting a one-way ANOVA plus multiple testing method and controlling the within-group error. Differences were considered statistically significant at $p<0.05$ and $p<0.01$.

\section{RESULTS}

\subsection{The Effect of EA on the Viability of BV2 Cells}

To determine whether EA affects the growth of BV2 cells, we tested the effect of different concentrations of EA $(0-32 \mu \mathrm{M})$ on the survival rate of $\mathrm{BV} 2$ cells and $\mathrm{LDH}$ release. The results of CCK8 showed that EA no more than $16 \mu \mathrm{M}$ did not affect the survival rate of BV2 cells (Figure 1C). The results of LDH showed 

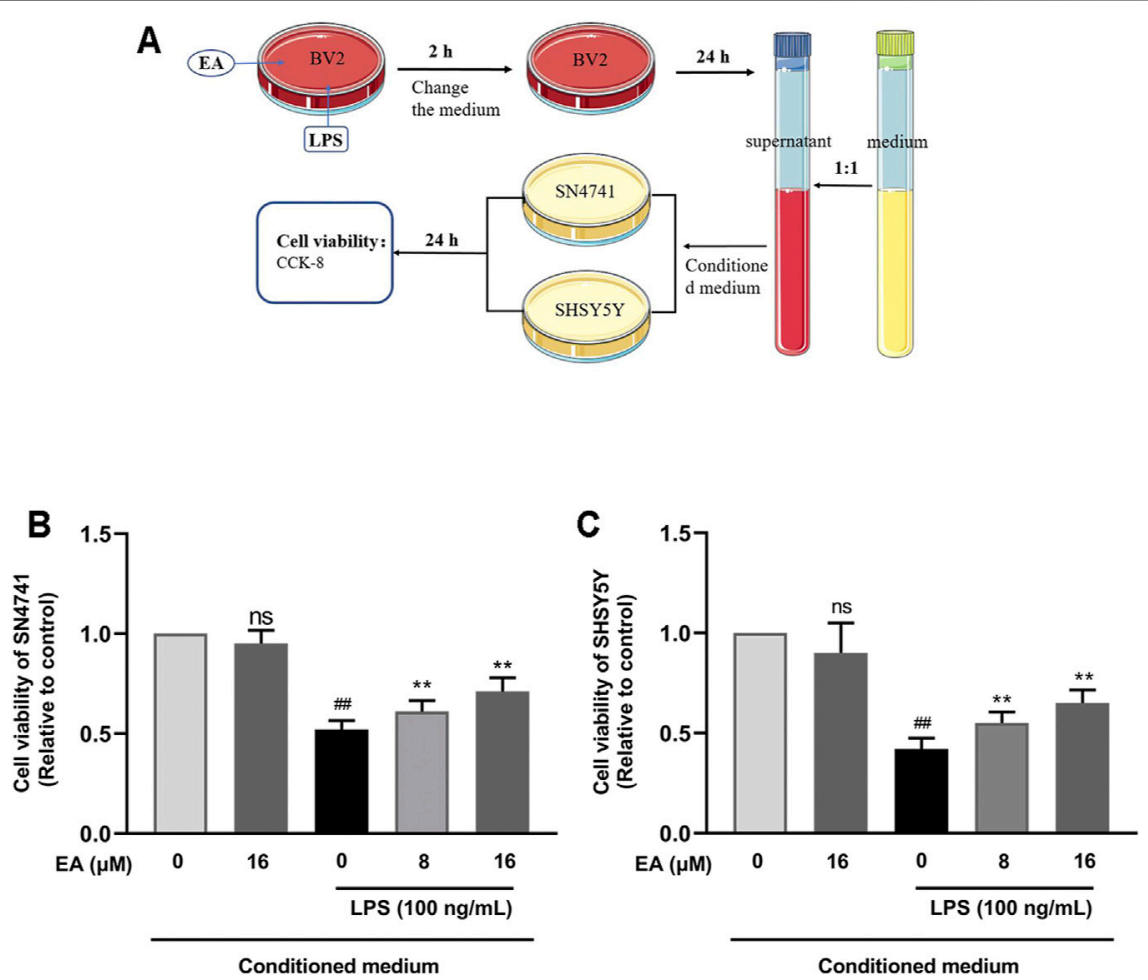

FIGURE 5 | EA eases microglia-mediated neuron death in SN4741 cells and SHSY5Y cells. We treated BV2 cells with EA (16 $\mu$ M) and LPS (100 ng/ml) for 2 h, and then changed the medium. After $24 \mathrm{~h}$, the medium was collected and mixed with the fresh medium in a 1:1 ratio as the conditioned medium (A). Then the effect of the conditioned medium on the survival rate of SN4741 cells (B) and SHSY5Y cells (C) was detected by CCK8 experiment. Results are represented as means \pm SD $(n=4)$. ${ }^{\# \#} p<0.01$ vs. control group. ${ }^{* *} p<0.01$ vs. LPS-exposed group.

that EA no more than $16 \mu \mathrm{M}$ did not affect the $\mathrm{LDH}$ release of BV2 cells (Figure 1D). These results demonstrated that EA no more than $16 \mu \mathrm{M}$ did not show potential toxic effects on BV2 cells.

\subsection{EA Inhibits the Production of Inflammatory Mediators}

When inflammation occurs, immune cells release a large amount of pro-inflammatory factors (IL- 6 and TNF- $\alpha$ ) and pro-inflammatory enzymes (iNOS and COX-2), which are considered one of the causes of damage to the surrounding tissues and neurons. To clarify the anti-inflammatory effect of EA, we treated cells with EA $(16 \mu \mathrm{M})$ for $1 \mathrm{~h}$ and stimulated them with LPS $(100 \mathrm{ng} / \mathrm{ml})$ for another 12 (mRNA) or $24 \mathrm{~h}$ (protein). The mRNA expression of pro-inflammatory mediators [iNOS (Figure 2A), COX-2 (Figure 2B), IL-6 (Figure 2C), and TNF-a (Figure 2D)] was measured by the quantitative PCR method, and the protein expression was measured by ELISA (IL-6 (Figure 2H), TNF-a (Figure 2I), and Western blot [iNOS (Figures 2E,F) and COX-2 (Figures 2E,G)] technology. Results showed that EA inhibited the mRNA and protein expression of inflammatory mediators.

\subsection{EA Inhibits Inflammation Through the PI3K/Akt Signal Pathway in BV2 Cells}

The PI3K/Akt is an intracellular signal transduction pathway responsible for cell proliferation and survival. In the experiment, we investigated the effect of EA on the PI3K/Akt signal pathway. We treated BV2 cells at different times $(0,15,30$, and $60 \mathrm{~min})$ with EA $(16 \mu \mathrm{M})$ and measured the phosphorylation changes of PI3K/Akt signal pathways. Results showed that EA promoted the activation of PI3K (Figures 3A,B) and Akt (Figures 3A,C) pathway in the BV2 cells. Thereafter, we treated BV2 cells with PI3K pathway inhibitors (LY294002, $5 \mu \mathrm{M}$ ) for $6 \mathrm{~h}$ and measured the activation of the PI3K/ Akt pathway. Results showed that LY294002 could block the activation of PI3K (Figures 3D,E) and Akt (Figures 3D,F) pathway by EA to a certain extent. Similarly, Akt pathway inhibitor (MK2206, $10 \mu \mathrm{M}$ for $6 \mathrm{~h}$ ) treatment inhibited the activation of the Akt pathway by EA (Figures 3G,H).

In further studies, we treated BV2 cells with pathway inhibitors (LY294002 or MK2206) for $6 \mathrm{~h}$ and measured the expression of pro-inflammatory mediators. The results showed that treatment with pathway inhibitors inhibited the regulatory effect of EA on inflammatory mediators [iNOS (Figure 3K), COX-2 (Figure 3L), IL-6 (Figure 3I), and TNF- $a$ (Figure 3J)] in LPS-exposed BV2 cells. These results demonstrated that EA inhibits inflammation through the PI3K/Akt signal pathway. 

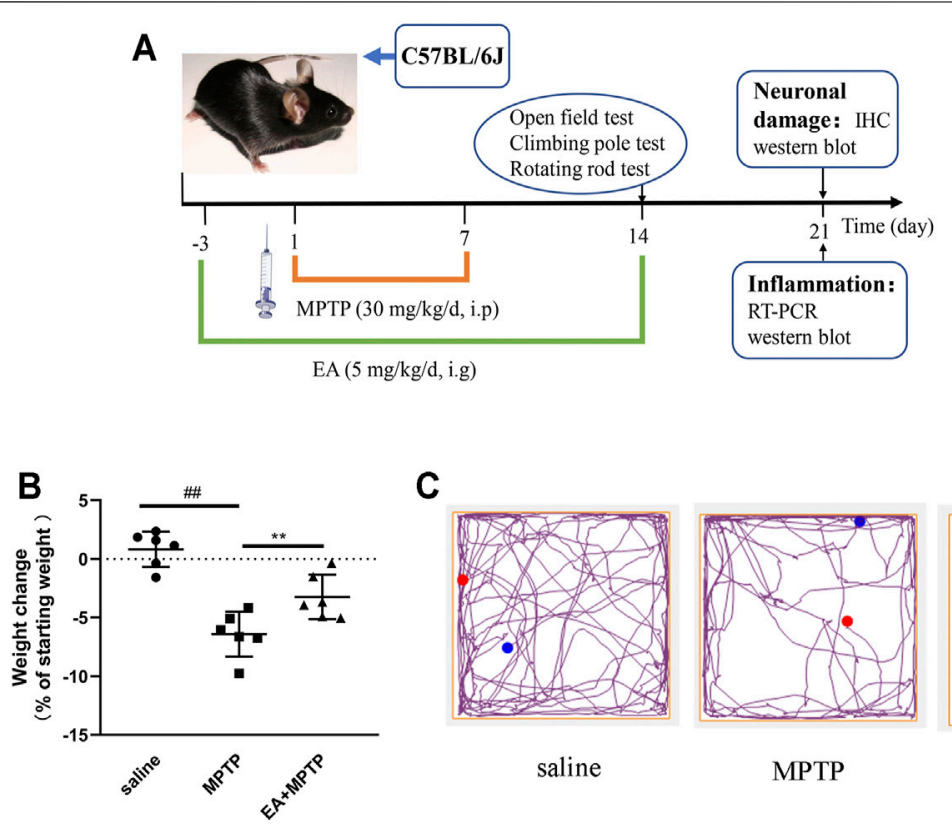

C

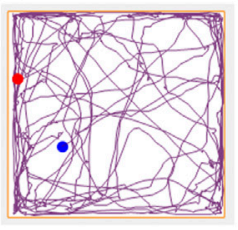

saline

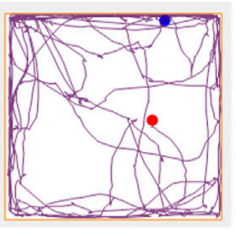

MPTP

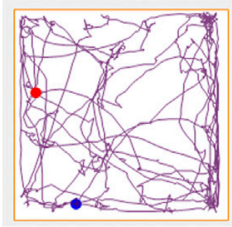

EA+MPTP
D

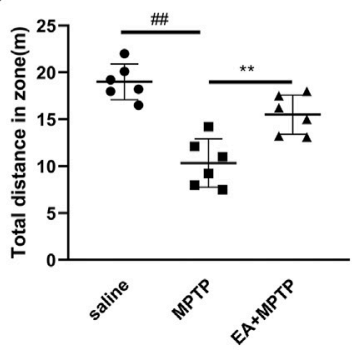

E

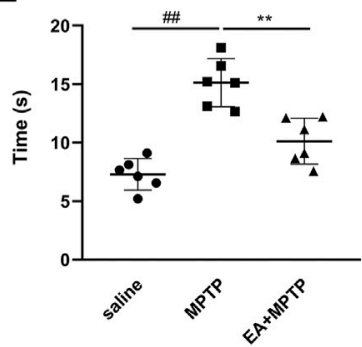

$\mathbf{F}$

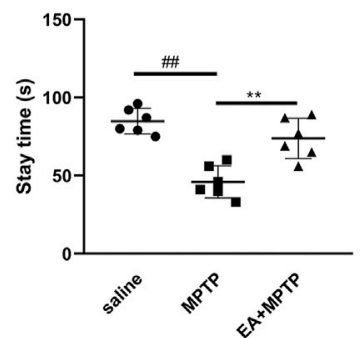

FIGURE 6 | EA improves MPTP-induced body weight loss and locomotor activity decreasing in a mouse model of PD. Mice were given EA (5 mg/kg) by gavage for $17 \mathrm{~d}$ and MPTP (30 mg/kg) by intraperitoneal injection for $7 \mathrm{~d}$ (A). Then we examined the effect of EA on body weight loss (B) of mice and the locomotor activity via openfield (C,D), rod climbing (E), and rod rotating (F) experiments. Results are represented as means $\pm S D(n=6) .{ }^{\# \#} p<0.01$ vs. saline group. ${ }^{* *} p<0.01$ vs. MPTP group.

\subsection{EA Inhibits NF-kB and MAPK Pathways in BV2 Cells}

Studies have revealed that NF- $\kappa \mathrm{B}$ and MAPK signal pathways play a crucial role in the process of inflammation, and their activation can regulate the transcription of inflammatory mediators. In order to clarify the mechanism of EA regulating inflammatory mediators, we studied the effect of EA on NF- $\kappa B$ and MAPK pathway activation. We treated the cells with EA $(16 \mu \mathrm{M})$ for $1 \mathrm{~h}$ and then stimulated with LPS $(100 \mathrm{ng} / \mathrm{ml})$ for another $1 \mathrm{~h}$. Then we detected the

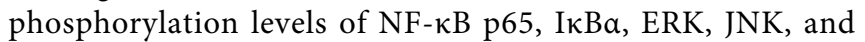
p38 and their expression by Western blot. Results proved that EA inhibited the phosphorylation of NF- $\kappa \mathrm{B}$ p65 (Figures 4A,B), IкBa (Figures 2 A,C), ERK (Figures 4 E,F), JNK (Figures 4E,G), and p38 (Figures $\mathbf{4} \mathbf{E}, \mathbf{H}$ ), and the degradation of I $\mathrm{KBa}$ (Figures 4 A,D). These results demonstrated that EA inhibited the activation of NF- $\kappa \mathrm{B}$ and MAPK signal pathways in LPS-exposed BV2 cells.

\subsection{EA Eases Microglia-Mediated Neuron Death in SN4741 and SHSY5Y Cells}

To study the neuroprotective effect of EA on neural cells, we cultured two types of neuron cell lines (SN4741 and SHSY5Y). We incubated BV2 cells with EA $(16 \mu \mathrm{M})$ and LPS $(100 \mathrm{ng} / \mathrm{ml})$ for $2 \mathrm{~h}$ and then changed the medium. After $24 \mathrm{~h}$, the medium was collected and mixed with fresh medium in a 1:1 ratio as the conditioned medium (Figure 5A). When the density of SN4741 and SHSY5Y cells was $50-60 \%$, the medium was changed to a conditional medium, and then the survival rate of cells was detected through CCK8 experiment. Results showed that EA eases microglia-mediated neuron death in SN4741 (Figure 5B) and SHSY5Y cells (Figure 5C).

\subsection{EA Improves MPTP-Induced Body Weight Loss and Locomotor Activity Decreasing in a Mouse Model of PD}

The main clinical manifestation of PD is decreased or loss of locomotor activity. We detected the effects of EA on weight loss 
A

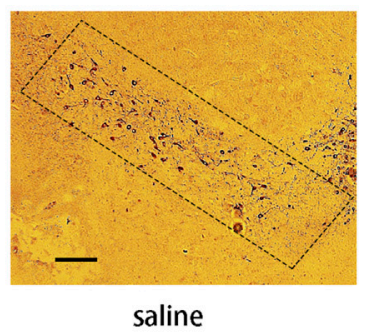

B

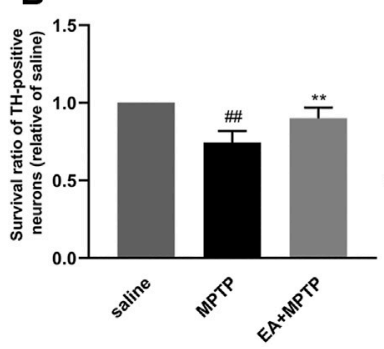

E

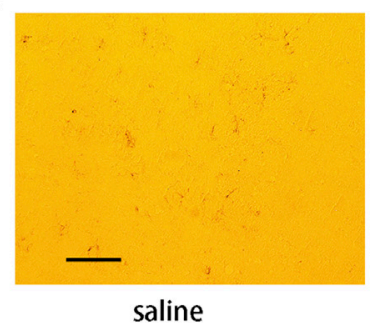

saline

\section{F}

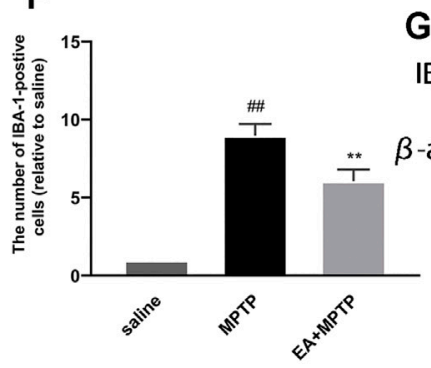

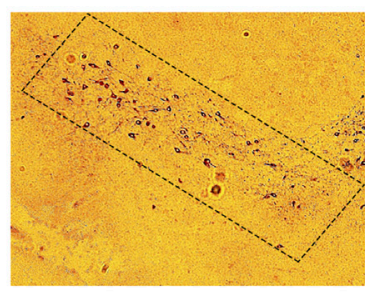

MPTP
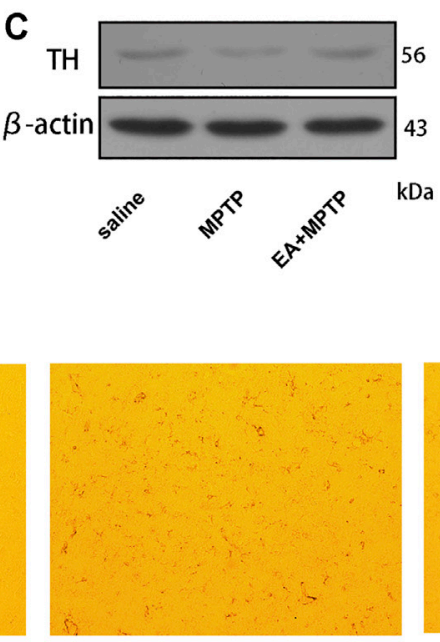

MPTP

G IBA-1

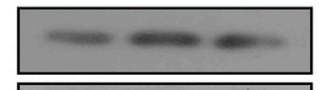

in
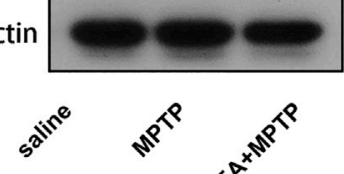

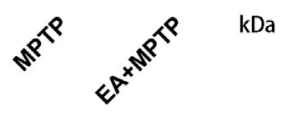

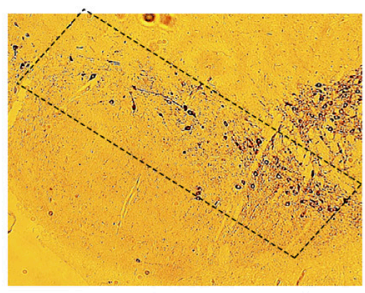

$\mathrm{EA}+\mathrm{MPTP}$
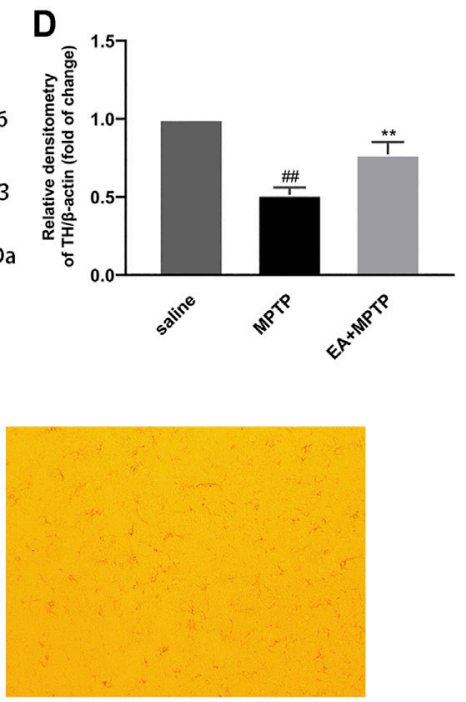

EA+MPTP

$\mathbf{H}$

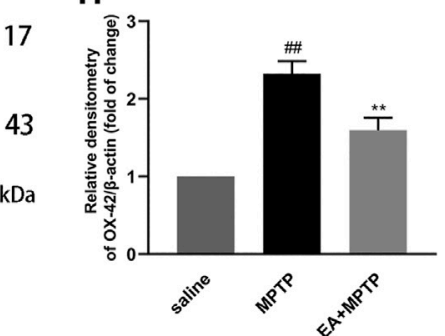

FIGURE 7 |EA reduces MPTP-induced loss of dopaminergic neurons and the activation of microglia in a mouse model of PD. We obtained mouse midbrain tissue, formaldehyde fixation, and paraffin section. The number of TH-positive cells was detected by immunohistochemical assay (100 $\mu$ m) (A,B). The expression of TH protein in the midbrain region of mice was detected by Western blot assay (C,D). The number of IBA-1-positive cells was detected by immunohistochemical assay (30 $\mu$ m) $\mathbf{( E , F ) . ~ T h e ~ e x p r e s s i o n ~ o f ~ I B A - 1 ~ p r o t e i n ~ i n ~ t h e ~ m i d b r a i n ~ r e g i o n ~ o f ~ m i c e ~ w a s ~ d e t e c t e d ~ b y ~ W e s t e r n ~ b l o t ~ a s s a y ~}(\mathbf{G}, \mathbf{H})$. Results are represented as means \pm SD $(n=4) .{ }^{\# \#} p<0.01$ vs. saline group. ${ }^{* *} p<0.01$ vs. MPTP group.

and locomotor activity in MPTP-induced PD mice. Results showed that EA $(5 \mathrm{mg} / \mathrm{kg})$ improved MPTP-induced body weight loss (Figure 6B). Open-field experiments showed that EA increased the total distance mice traveled in the open field (Figures 6 C,D). The pole climbing experiment showed that EA reduced the climbing experiment duration in mice (Figure 6E). The rod rotation test showed that EA increased the duration of mice on the rod rotation fatigue meter (Figure 6F). These results demonstrated that EA improves MPTP-induced body weight loss and locomotor activity decreasing.

\subsection{EA Reduces MPTP-Induced Loss of Dopaminergic Neurons and the Activation of Microglia in a Mouse Model of PD}

The main pathological feature of $\mathrm{PD}$ is the damage of dopaminergic neurons in the substantia nigra of the midbrain. To clarify the role of EA, we examined the effect of EA $(5 \mathrm{mg} / \mathrm{kg})$ on the damage of dopaminergic neurons in the substantia nigra of the midbrain in mice. The results showed that EA improved MPTP-induced loss of dopaminergic neurons (Figures 7A,B). $\mathrm{TH}$ is a rate-limiting enzyme synthesized by dopaminergic 

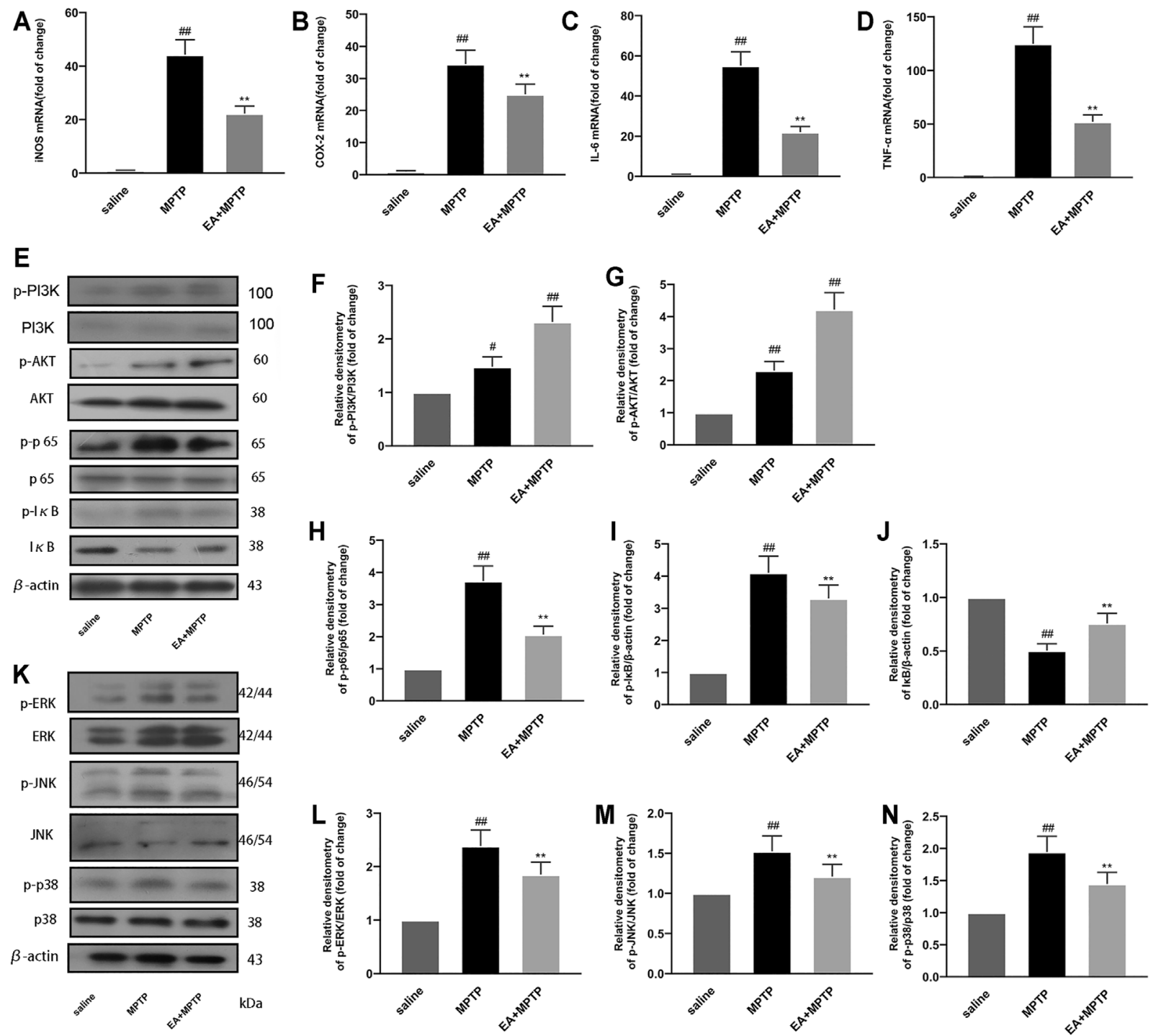

FIGURE 8 | EA inhibits MPTP-induced inflammation in a mouse model of PD. We obtained mouse midbrain tissue. The mRNA expression of inflammatory mediators [iNOS (A), COX-2 (B), IL-6 (C), and TNF- $\alpha$ (D)] was detected using quantitative PCR experiment. The protein expression of PI3K/Akt (E-G), NF- $\mathbf{k B}$ (E-J), and MAPK (K-N) pathways was detected by Western blot experiment. Results are represented as means \pm SD $(n=4)$. ${ }^{\# \#} p<0.01$ vs. saline group. ${ }^{* *} p<0.01$ vs. MPTP group.

neurons. We also detected the protein expression of $\mathrm{TH}$ in the midbrain by Western blot (Figures 7 C,D). The results demonstrated that EA inhibited the reduction of $\mathrm{TH}$ protein induced by MPTP.

The pathogenesis of $\mathrm{PD}$ is accompanied by excessive activation of microglia. In order to study the effect of EA, we tested the effect of EA on the activation of microglia. Immunohistochemical results showed that EA inhibited the number of IBA-1-positive cells in the substantia nigra (Figures 7E,F). Western blot results showed that EA inhibited the protein expression of IBA-1 in the mouse midbrain (Figures $\mathbf{7 G}, \mathbf{H}$ ). The results demonstrated that EA inhibited the activation of microglia.

\subsection{EA Inhibits Inflammation in the MPTP-Induced Mouse PD Model}

To further investigate the mechanism by which EA exerts its neuroprotective effect, we investigated the effects of EA $(5 \mathrm{mg} / \mathrm{kg})$ on mediators and inflammatory pathways in a PD mouse model. The results of fluorescence quantitative PCR showed that EA inhibited the mRNA expression of pro-inflammatory mediators (iNOS (Figure 8A), COX-2 (Figure 8B), IL-6 (Figure 8C), and TNF- $\alpha$ (Figure 8D). The results of Western blot showed that EA activated PI3K/Akt (Figures 8E-G) and inhibited NF- $\kappa \mathrm{B}$ (Figures 8E,H-J) and MAPK (Figures $8 \mathrm{~K}-\mathbf{N}$ ) signal pathways. These results demonstrated that EA inhibits MPTPinduced inflammation in the MPTP-induced mouse PD model. 


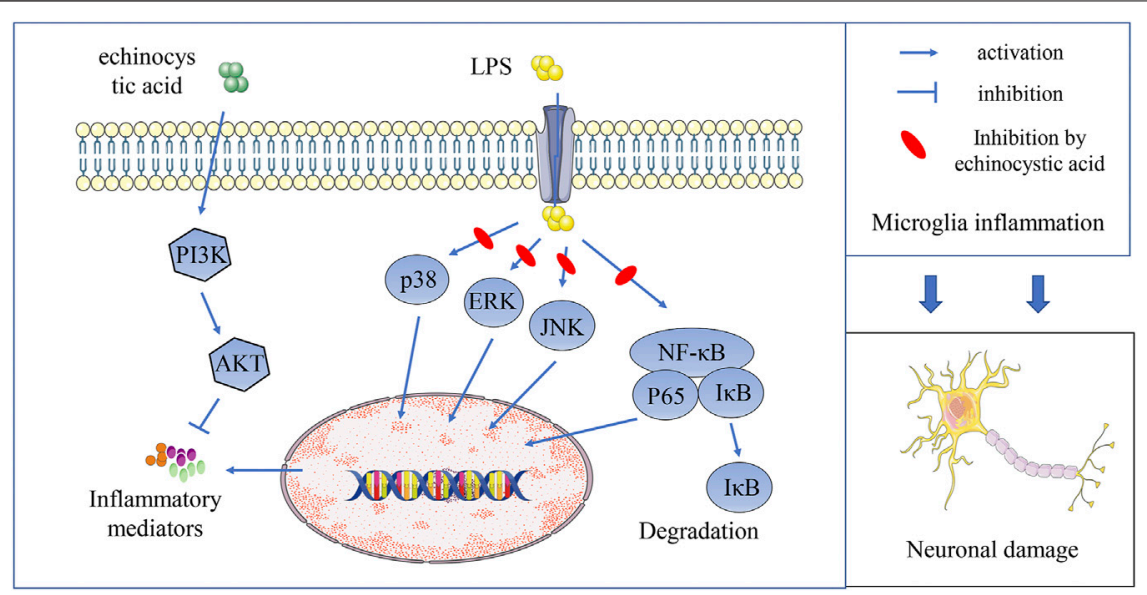

FIGURE 9 | EA inhibits neuroinflammation and exerts neuroprotective effects by activating PI3K/Akt signaling and inhibiting NF-kB and MAPK signal pathways.

\section{DISCUSSION}

$\mathrm{PD}$, the second most prevalent neurodegenerative disorder affecting human health, is characterized by dopaminergic neuron damage in the substantia nigra of the midbrain, resulting in reduced dopamine content in the striatum, which leads to movement disorders in patients (Dauer and Przedborski, 2003; Hawkes et al., 2010). Therefore, the treatment of PD mainly focuses on increasing the number of dopaminergic neurons in the midbrain substantia nigra of the patient or enhancing the capacity of the remaining dopaminergic neurons to produce dopamine. In our experiment, we intraperitoneally injected MPTP into mice to establish a PD mouse model, and then studied the effects of EA on the motor behavior and dopaminergic neurons in the substantia nigra of PD mice. The results revealed that EA could inhibit MPTP-induced damage of dopaminergic neurons in the mice and improve their movement disorders. However, the mechanism by which EA protects neurons is unclear.

Studies have revealed that neuroinflammation is involved in the process of PD. When PD occurs, neurons are damaged, and the signal from the damaged neurons stimulates the body's innate immune response, followed by the proliferation of immune cells that gather at the injured site to remove the damaged tissues and harmful factors. However, excessive immune cells and continuous inflammatory response lead to pro-inflammatory mediator accumulation, which further aggravates neuronal damage (Ishiki et al., 2017; Han et al., 2019; Qi et al., 2019). Therefore, inhibition of neuroinflammatory responses is of great significance in alleviating $\mathrm{PD}$. In our experiment, we investigated the effect of EA on neuroinflammatory responses in MPTPinduced PD mice. The results revealed that EA inhibited the inflammatory response in the midbrain region of PD mice.

Microglia cells are the main effector cells of neuroinflammation (Ekdahl et al., 2009; Cameron and Landreth, 2010). BV2 is a microglia cell line cultured artificially (Henn et al., 2009). LPS is a Gram-negative bacterial cell wall component and can induce inflammatory responses (Huang et al., 1995; Peng et al., 2018). In our experiment, we stimulated BV2 cells with LPS to induce inflammatory response and surveyed the effect of EA on neuroinflammation. The results showed that EA inhibited the production of inflammatory mediators in BV2 cells. We used the supernatant of BV2 cells treated with EA and LPS to incubate two kinds of neuronal cell lines (SN4741 and SHSY5Y cells) and discovered that EA treatment improved the neurotoxicity mediated by microglia activation and played a neuroprotective role.

PI3K (phosphatidylinositol kinase) is a protein dimer composed of the regulatory subunit P85 and the catalytic subunit P110. When PI3K binds to growth factor receptors (such as EGFR), it changes the protein structure of Akt and activates it. PI3K activates or inhibits the activity of a series of downstream substrates through phosphorylation, thereby regulating cell proliferation, differentiation, apoptosis, and migration phenotypes (Gang et al., 2010; Alzahrani, 2019; Ghoneum and Said, 2019). In our experiment, we investigated the effect of EA on the PI3K/Akt pathway and found that EA activated the PI3K/Akt pathway. However, after inhibitors blocked the PI3K/Akt pathway, the inhibitory effect of EA on pro-inflammatory mediators was weakened to a certain extent. These results proved that EA inhibited the production of pro-inflammatory mediators by activating the PI3K/Akt signal pathway.

Nuclear factor-kappa B $(\mathrm{NF}-\kappa \mathrm{B})$ and mitogen-activated protein kinase (MAPK) are two critical inflammatory pathways that regulate the transcription of inflammatory mediators after activation. NF- $\kappa \mathrm{B}$ is composed of two subunits, p65 and I $\mathrm{kB}$, in the cytoplasm. After activation, the $I \kappa B$ protein is separated and degraded by the two subunits, while p65 is phosphorylated into the nucleus and regulates the transcription of cytokines (Trickler et al., 2005; Mc Guire et al., 2013; Scott and Roifman, 2019). In our experiment, we investigated the effect of EA on the NF- $\kappa B$ pathway. Results showed that EA inhibited the phosphorylation of I $\mathrm{B}$ and p65 
and degradation of IKB. Three subunits are present downstream of the MAPK pathway: ERK, P38, and JNK (Wagner and Nebreda, 2009; Costa et al., 2016; Seger and Wexler, 2016). In our experiment, we surveyed the effect of EA on the MAPK pathway. Results showed that EA inhibited the phosphorylation of ERK, P38, and JNK. In vivo studies have also confirmed that EA activates the PI3K/ Akt pathway and inhibits the NF- $\kappa B$ and MAPK signal pathways.

In conclusion, our study discovered that EA could improve PD symptoms in mice by activating PI3K/Akt and inhibiting NF- $\kappa \mathrm{B}$ and MAPK signal pathways, inhibiting neuroinflammation and playing a neuroprotective role (Figure 9). EA as a plant extract with low side effects is economical and readily available, so it is expected to be further developed and utilized. Our study would contribute to further search for effective treatments for PD.

\section{DATA AVAILABILITY STATEMENT}

The original contributions presented in the study are included in the article/Supplementary Material; further inquiries can be directed to the corresponding authors.

\section{REFERENCES}

Alstadhaug, K. B., Fykse Halstensen, R., and Odeh, F. (2017). Progressive Multifocal Leukoencephalopathy in a Patient with Systemic Mastocytosis Treated with Cladribine. J. Clin. Virol. 88 (Complete), 17-20. doi:10.1016/ j.jcv.2016.12.005

Alzahrani, A. S. (2019). PI3K/Akt/mTOR Inhibitors in Cancer: At the Bench and Bedside. Semin. Cancer Biol. 59, 125-132. doi:10.1016/j.semcancer.2019.07.009

Bartels, A. L., and Leenders, K. L. (2010). Neuroinflammation in the Pathophysiology of Parkinson's Disease: Evidence from Animal Models to Human In Vivo Studies with [11C]-Pk11195 PET. Mov Disord. 22 (13), 1852-1856. doi:10.1002/mds.21552

Bomalaski, M. N., Claflin, E. S., Townsend, W., and Peterson, M. (2017). Zolpidem for the Treatment of Neurologic Disorders: A Systematic Review. Jama Neurol. 74, 1130. doi:10.1001/jamaneurol.2017.1133

Cameron, B., and Landreth, G. E. (2010). Inflammation, Microglia, and Alzheimer's Disease. Neurobiol. Dis. 37 (3), 503-509. doi:10.1016/ j.nbd.2009.10.006

Chen, B., Zhao, Y., Li, W., Hang, J., Yin, M., and Yu, H. (2020). Echinocystic Acid Provides a Neuroprotective Effect via the PI3K/AKT Pathway in Intracerebral Haemorrhage Mice. Ann. Transl Med. 8 (1), 6. doi:10.21037/atm.2019.12.35

Chung, Y. C., Ko, H. W., Bok, E., Park, E. S., Huh, S. H., Nam, J. H., et al. (2010). The Role of Neuroinflammation on the Pathogenesis of Parkinson's Disease. BMB Rep. 43 (4), 225-232. doi:10.5483/bmbrep.2010.43.4.225

Costa, A. P., Lopes, M. W., Rieger, D. K., Barbosa, S. G., Gonçalves, F. M., Xikota, J. C., et al. (2016). Differential Activation of Mitogen-Activated Protein Kinases, ERK 1/2, p38(MAPK) and JNK P54/p46 during Postnatal Development of Rat Hippocampus. Neurochem. Res. 41 (5), 1160-1169. doi:10.1007/s11064-0151810-z

Dauer, W., and Przedborski, S. (2003). Parkinson's Disease. Neuron 39 (6), 889-909. doi:10.1016/s0896-6273(03)00568-3

Deretic, V. (2021). Autophagy in Inflammation, Infection, and Immunometabolism. Immunity 54 (3), 437-453. doi:10.1016/j.immuni.2021.01.018

Dhaneshwar, N. N., Sawaikar, D., Narayanan, C. R., Tavale, S. S., and Row, T. (2010). Structure of an Oxidation Product of Echinocystic Acid. Acta Crystallogr. 43 (1), 66-68. doi:10.1107/s0108270187096975

\section{ETHICS STATEMENT}

The animal study was reviewed and approved by the Institutional Animal Care and Use Committee of Jilin University (Changchun, China, Protocol No. SY202107005).

\section{AUTHOR CONTRIBUTIONS}

$\mathrm{DH}, \mathrm{AZ}, \mathrm{YL}$, and $\mathrm{BH}$ accomplished most of the experiments, analyzed the results, and wrote the manuscript. DL designed this study. YS and HW took part in various aspects of the study, and read and revised the first draft. BY, YH, XG, and SF also participated in the research. All authors read and approved the final manuscript.

\section{FUNDING}

This work was funded by the National Natural Science Foundation of China (Project No. 31772547), the Jilin Scientific and Technological Development Program (Project No. 20200703011ZP), the Jilin University Graduate Innovative Research Program (Project No. 101832020CX331), and the Fundamental Research Funds for Central Universities.

Ekdahl, C. T., Kokaia, Z., and Lindvall, O. (2009). Brain Inflammation and Adult Neurogenesis: the Dual Role of Microglia. Neuroscience 158 (3), 1021-1029. doi:10.1016/j.neuroscience.2008.06.052

Elkouzi, A., Vedam-Mai, V., Eisinger, R. S., and Okun, M. S. (2019). Emerging Therapies in Parkinson Disease - Repurposed Drugs and New Approaches. Nat. Rev. Neurol. 15, 204-223. doi:10.1038/s41582-019-0155-7

Fu, S. B., Feng, X., Meng, Q. F., Cai, Q., and Sun, D. A. (2018). Two New Echinocystic Acid Derivatives Catalyzed by Filamentous Fungus Gliocladium Roseum CGMCC 3.3657. Nat. Prod. Res. 33 (13), 1842-1848. doi:10.1080/ 14786419.2018.1477148

Gang, S., Ouyang, G., and Bao, S. (2010). The Activation of Akt/PKB Signaling Pathway and Cell Survival. J. Cell Mol. Med. 9 (1), 59-71. doi:10.1111/j.15824934.2005.tb00337.x

Ghoneum, A., and Said, N. (2019). PI3K-AKT-mTOR and NFkB Pathways in Ovarian Cancer: Implications for Targeted Therapeutics. Cancers (Basel) 11 (7), 949. doi:10.3390/cancers 11070949

Han, X. J., Sun, S., Sun, Y., Song, Q., Zhu, J., Song, N., et al. (2019). Small MoleculeDriven NLRP3 Inflammation Inhibition via Interplay between Ubiquitination and Autophagy: Implications for Parkinson Disease. Autophagy 15, 1860-1881. doi:10.1080/15548627.2019.1596481

Hawkes, C. H., Del Tredici, K., and Braak, H. (2010). Parkinson's Disease: a DualHit Hypothesis. Neuropathol. Appl. Neurobiol. 33 (6), 599-614. doi:10.1111/ j.1365-2990.2007.00874.x

Henn, A., Lund, S., Hedtjärn, M., Schrattenholz, A., Pörzgen, P., and Leist, M. (2009). The Suitability of BV2 Cells as Alternative Model System for Primary Microglia Cultures or for Animal Experiments Examining Brain Inflammation. Altex 26 (2), 83-94. doi:10.14573/altex.2009.2.83

Hopperton, K. E., Mohammad, D., Trépanier, M., Giuliano, V., and Bazinet, R. P. (2017). Markers of Microglia in post-mortem Brain Samples from Patients with Alzheimer's Disease: a Systematic Review. Mol. Psychiatry 23, 177-198. doi:10.1038/mp.2017.246

Houman, H. (2018). Parkinson Disease. Ann. Intern. Med. 169 (5), ITC33. doi:10.7326/AITC201809040

Huang, K., Fishwild, D. M., Wu, H. M., and Dedrick, R. L. (1995). Lipopolysaccharide-induced E-Selectin Expression Requires Continuous Presence of LPS and Is Inhibited by Bactericidal/permeability-Increasing Protein. Inflammation 19 (3), 389-404. doi:10.1007/BF01534395 
Ishiki, H. M., Filho, J., Da, M. S., Scotti, M. T., and Scotti, L. (2017). Computeraided Drug Design Applied to Parkinson Targets. Curr. Neuropharmacology 15 (6), 865-880. doi:10.2174/1570159X15666171128145423

Jæger, D., Ndi, C. P., Crocoll, C., Simpson, B. S., Khakimov, B., Guzman-Genuino, R. M., et al. (2017). Isolation and Structural Characterization of Echinocystic Acid Triterpenoid Saponins from the Australian Medicinal and Food Plant Acacia Ligulata. J. Nat. Prod. 80 (10), 2692-2698. doi:10.1021/acs.jnatprod.7b00437

Joh, E. H., Gu, W., and Kim, D. H. (2012). Echinocystic Acid Ameliorates Lung Inflammation in Mice and Alveolar Macrophages by Inhibiting the Binding of LPS to TLR4 in NF-Kb and MAPK Pathways. Biochem. Pharmacol. 84 (3), 331-340. doi:10.1016/j.bcp.2012.04.020

Kan, C., Trevor, A., and Castagnoli, N. (1984). Metabolism of the Neurotoxic Tertiary Amine, MPTP, by Brain Monoamine Oxidase. Biochem. Biophysical Res. Commun. 120 (2), 574-578. doi:10.1016/0006-291x(84)91293-2

Lee, J-K., TranMalú, T., and Tansey, G. (2009). Neuroinflammation in Parkinson's Disease. J. Neuroimmune Pharmacol. 4 (4), 419-429. doi:10.1007/s11481-009-9176-0

Liu, J., Lv, Y. W., Shi, J. L., Ma, X. J., Chen, Y., Zheng, Z. Q., et al. (2017). AntiAnxiety Effect of (-)-Syringaresnol-4-O- $\beta$-D-Apiofuranosyl-( $1 \rightarrow 2)-\beta$-DGlucopyranoside from Albizzia Julibrissin Durazz (Leguminosae). Molecules 22 (8), 1331. doi:10.3390/molecules22081331

Lu, Y. C., Yeh, W. C., and Ohashi, P. S. (2008). LPS/TLR4 Signal Transduction Pathway. Cytokine 42 (2), 145-151. doi:10.1016/j.cyto.2008.01.006

Mc Guire, C., Prinz, M., Beyaert, R., and van Loo, G. (2013). Nuclear Factor Kappa B (NF-Kb) in Multiple Sclerosis Pathology. Trends Mol. Med. 19 (10), 604-613. doi:10.1016/j.molmed.2013.08.001

Nakano-Kobayashi, A., Fukumoto, A., Morizane, A., Nguyen, D. T., Le, T. M., Hashida, K., et al. (2020). Therapeutics Potentiating Microglial P21-Nrf2 axis Can rescue Neurodegeneration Caused by Neuroinflammation. Sci. Adv. 6 (46), eabc1428. doi:10.1126/sciadv.abc1428

Peng, Z., Liang, W., Wang, F., Xu, Z., Xie, Z., Lian, Z., et al. (2018). Genetic and Phylogenetic Characteristics of Pasteurella Multocida Isolates from Different Host Species. Front. Microbiol. 9, 1408. doi:10.3389/fmicb.2018.01408

Pereira, D. R., Weber, S. A. T., Hook, C., de Albuquerque, V. H. C., and Papa, J. P. (2018). A Survey on Computer-Assisted Parkinson's Disease Diagnosis. Artif. intelligence Med. 95, 48-63. doi:10.1016/j.artmed.2018.08.007

Pollak, P. (2004). Movement Disorders: Parkinson's Disease Dominates. Lancet Neurol. 3 (1), 15. doi:10.1016/s1474-4422(03)00615-x

Przedborski, S., Jackson-Lewis, V., Yokoyama, R., Shibata, T., and Dawson, V. (1996). Role of Neuronal Nitric Oxide in 1-Methyl-4-Phenyl-1,2,3,6Tetrahydropyridine (MPTP)-induced Dopaminergic Neurotoxicity. Proc. Natl. Acad. Sci. 93, 4565-4571. doi:10.1073/pnas.93.10.4565

Qi, G., Mi, Y., Fan, R., Li, R., Liu, Z., and Liu, X. (2019). Nobiletin Protects against Systemic Inflammation-Stimulated Memory Impairment via MAPK and NF-
Kb Signaling Pathways. J. Agric. Food Chem. 67, 5122-5134. doi:10.1021/ acs.jafc.9b00133

Ramli, N. Z., Yahaya, M. F., Tooyama, I., and Damanhuri, H. A. (2020). A Mechanistic Evaluation of Antioxidant Nutraceuticals on Their Potential against Age-Associated Neurodegenerative Diseases. Antioxidants (Basel) 9 (10), 1019. doi:10.3390/antiox9101019

Scott, O., and Roifman, C. M. (2019). NF-кB Pathway and the Goldilocks Principle: Lessons from Human Disorders of Immunity and Inflammation. J. Allergy Clin. Immunol. 143 (5), 1688-1701. doi:10.1016/j.jaci.2019.03.016

Seger, R., and Wexler, S. (2016). The MAPK Signaling Cascades. Encyclopedia Cel Biol. 3 (9), 122-127. doi:10.1016/b978-0-12-394447-4.30014-1

Shao, Y., Poobrasert, O., Ho, C. T., Chin, C. K., and Cordell, G. A. (1996). An Echinocystic Acid Saponin Derivative from Kalimeris Shimadae. Phytochemistry 43 (1), 195-200. doi:10.1016/0031-9422(96)00247-6

Trickler, W. J., Mayhan, W. G., and Miller, D. W. (2005). Brain Microvessel Endothelial Cell Responses to Tumor Necrosis Factor-Alpha Involve a Nuclear Factor Kappa B (NF-kappaB) Signal Transduction Pathway. Brain Res. 1048 (12), 24-31. doi:10.1016/j.brainres.2005.04.028

Wagner, E. F., and Nebreda, A. R. (2009). Signal Integration by JNK and P38 MAPK Pathways in Cancer Development. Nat. Rev. Cancer 9 (8), 537-549. doi:10.1038/nrc2694

Yu, H., Li, W., Cao, X., Wang, X., Zhao, Y., Song, L., et al. (2019). Echinocystic Acid, a Natural Plant Extract, Alleviates Cerebral Ischemia/reperfusion Injury via Inhibiting the JNK Signaling Pathway. Eur. J. Pharmacol. 861, 172610. doi:10.1016/j.ejphar.2019.172610

Conflict of Interest: The authors declare that the research was conducted in the absence of any commercial or financial relationships that could be construed as a potential conflict of interest.

Publisher's Note: All claims expressed in this article are solely those of the authors and do not necessarily represent those of their affiliated organizations, or those of the publisher, the editors, and the reviewers. Any product that may be evaluated in this article, or claim that may be made by its manufacturer, is not guaranteed or endorsed by the publisher.

Copyright (C) $2022 \mathrm{He}, \mathrm{Hu}$, Zhou, Liu, Huang, Su, Wang, Ye, He, Gao, Fu and Liu. This is an open-access article distributed under the terms of the Creative Commons Attribution License (CC BY). The use, distribution or reproduction in other forums is permitted, provided the original author(s) and the copyright owner(s) are credited and that the original publication in this journal is cited, in accordance with accepted academic practice. No use, distribution or reproduction is permitted which does not comply with these terms. 